\title{
Seguimiento con carga viral para virus Epstein- Barr en pacientes pediátricos con trasplante hepático
}

\begin{abstract}
Juan Gonzalo Mesa*
Beatriz Helena Aristizábal**

*Pediatra. Fellow de infectología pediátrica. Universidad CES. Medellín. Antioquia. Colombia.

**Bacterióloga. Mgtr en inmunología. Doctorado en ciencias básicas. Posdoctorado en biología molecular. Jefe del departamento de biología molecular. Hospital Pablo Tobón Uribe. Medellín. Antioquia. Colombia.

Correspondencia: Dr. Juan Gonzalo Mesa Monsalve. Dirección: Calle 41B sur 34-100 apartamento 511. Envigado. Antioquia. Colombia. Correo electrónico: jgmesa1981@yahoo.com

\section{RESUMEN}

Introducción: Los pacientes trasplantados son un reto desde todo punto de vista. La infección por el virus de Epstein-Barr es frecuente y su manejo suele ser difícil por la falta de medicamentos efectivos. Los pacientes con trasplante hepático tienen una alta incidencia de infección/reactivación por virus Epstein-Barr por el riesgo de primoinfección durante este periodo o la reactivación por inmunosupresión. Objetivos: Describir los hallazgos obtenidos con el uso de la carga viral para el virus de Epstein-Barr en el seguimiento de los pacientes pediátricos sometidos a trasplante hepático en una institución de cuarto nivel en Medellín, Colombia. Selección de pacientes: Se revisaron siete historias clínicas de pacientes con trasplante hepáticos escogidos al azar, obteniendo de ellas los datos demográficos, motivo de trasplante, momento de la aparición de la de la carga viral positiva por el virus de Epstein-Barr, evolución de la carga viral, efectos de los medicamentos inmunosupresores y antivirales, y el desenlace de los pacientes. Descripción de casos: La edad promedio de los pacientes al momento del trasplante fue de 28,4 meses, el efecto de los medicamentos antivirales como gangiclovir, valganciclovir, inmunoglobulina contra citomegalovirus, no parece ejercer una disminución adecuada y sostenida de la carga viral. Conclusiones: A pesar de las opciones terapéuticas disponibles para el herpes virus, según lo encontrado en la literatura actual y lo visto los pacientes evaluados, el grado de inmunosupresión parece ser el principal factor para el control de la replicación del virus de Epstein-Barr. MÉD UIS. 2015;28(3):393-401.
\end{abstract}

Palabras clave: Herpesvirus humano 4. Inmunosupresión. Trasplante de hígado.

\section{Follow up with viral load monitoring for Epstein-Barr virus in pediatric pacients with hepatic transplant}

\section{ABSTRACT}

Introduction: Transplant patients are a challenge from every point of view. Infection with Epstein- Barr virus is common and management is often hampered by the lack of effective medicaments available. Liver transplant patients have a high incidence of Epstein-Barr virus infection / reactivation because of the the risk of primary infection during this period or immunosuppression associated reactivation. Objectives: Describe the findings when using EBV viral load monitoring in liver transplant patients in an institution of the fourth level in Medellin, Colombia. Selection of patients: Seven medical records from liver transplant patients were randomly chosen obtaining from them demographic data, cause of transplantation, time of the Epstein-Barr virus detection, viral load evolution, effects of immunosuppressive medications over them and the patient's outcome. Description of patients: Average patient age at transplant was 28,4 months, the effect of antiviral drugs (gangiclovir, valganciclovir, cytomegalovirus immunoglobulin) seems not to be adequate and sustained in decreasing viral load. Conclusions: Although the therapeutic options available for Herpes virus, as found in current literature and seen in our patients, immunosupression degree seems to be the main factor for controlling EBV replication. MÉD UIS. 2015;28(3):393-401.

Keywords: Epstein-Barr virus infections. Immunosupresion. Liver transplantation. 
¿Cómo citar este artículo?: Mesa JG, Aristizábal BH. Seguimiento con carga viral para virus EpsteinBarr en pacientes pediátricos con trasplante hepático. MÉD UIS. 2015;28(3):393-401.

\section{INTRODUCCIÓN}

El Virus de Epstein-Barr (EBV, por sus siglas en inglés) es un gamma herpes virus con ADN de dos cadenas que codifica para aproximadamente 100 proteínas. Existen dos tipos diferentes denominados 1 o A y 2 o B. El tipo 1 es mas prevalente alrededor del mundo mientras que el 2 es más frecuente en África. Su transmisión ocurre principalmente por saliva ya sea en juguetes infectados, fómites o contacto físico, y ocurre usualmente entre los 4 y 30 años. La infección dura toda la vida pues se sabe que el $95 \%$ de la población adulta mundial está infectada'. En Colombia, no hay mucha información epidemiológica pero un estudio publicado en 2008 reportó una seroprevalencia del $84 \%$ sin discriminar entre niños y adultos ${ }^{2}$.

La infección por EBV comienza afectando las células epiteliales de la cavidad oral donde el virus se replica produciendo lisis celular y diseminación a otras células vecinas, posteriormente ocurre la viremia con lo que se invaden los órganos del sistema retículoendotelial y su principal célula blanco son los linfocitos B. A pesar de esto también puede afectar los linfocitos $T$ y las natural killer. Por este motivo, el virus es capaz de producir un espectro de enfermedades que dependen en gran medida del estado inmunológico del hospedero. La enfermedad prototipo de la infección por EBV es la mononucleosis infecciosa que se caracteriza por fiebre, odinofagia, adenopatías generalizadas, hepatoesplenomegalia y síntomas constitucionales como astenia y adinamia. La mononucleosis infecciosa es usualmente benigna y autolimitada en individuos inmunocompetentes' ${ }^{1}$, pero en pacientes inmunocomprometidos, la infección por EBV puede producir síndrome hemofagocítico, neumonitis intersticial linfoide y leucoplasia oral vellosa; también se ha asociado a enfermedades neoplásicas tales como carcinoma nasofaríngeo, linfoma de Burkitt, enfermedad de Hodgkin, leucemia linfoide crónica $^{3}$ y leiomiosarcoma ${ }^{1,4}$. El EBV es el principal responsable de la aparición de linfoma Burkitt en África (tipo endémico), el cual ocurre más frecuentemente en la niñez y demuestra la importancia de la primoinfección en la edad pediátrica ${ }^{4}$.

El trasplante hepático ha cambiado radicalmente el pronóstico de vida de muchos pacientes con falla hepática y los avances en diferentes áreas tales como el cuidado crítico, inmunología, enfermedades infecciosas, cirugía, enfermería, entre otras, han mejorado el pronóstico y la sobrevida de estos pacientes. La principales indicaciones para trasplante hepático pediátrico son la enfermedad colestásica como atresia de vías biliares, síndrome de Alagille, colestasis familiar, colangitis esclerosante primaria; enfermedades metabólicas ya sea por deficiencia de a1 antitripsina, tirosinemia, fibrosis quística, enfermedades del depósito de glucógeno, entre otras, cirrosis/hepatitis, tumores como hepatoblastoma, carcinoma hepatocelular, sarcoma; y otros más raros como hemangioendotelioma, hemocromatosis, Budd-Chiari, etc ${ }^{5}$.

Los pacientes trasplantados se han vuelto un reto desde el punto de vista médico pues son susceptibles a la adquisición o reactivación de diferentes infecciones, entre ellas las causadas por los virus de la familia Herpesviridae, particularmente el EBV, debido al delicado balance que deben tener entre la inmunosupresión para evitar el rechazo y el control de la infección por el sistema inmune. Dentro de las enfermedades asociadas más temidas al EBV se encuentra el Desorden Linfoproliferativo Postrasplante (DLP) que ocurre principalmente en niños ya que tienen más posibilidad de infectarse durante el periodo cercano al trasplante ${ }^{6}$. La incidencia de DLP difiere entre estudios, siendo en promedio de $9,7 \%$ y aparece meses a años luego del trasplante y de forma muy variable ${ }^{7}$.

Los pacientes trasplantados tienen deficiencias inmunológicas múltiples, sobre todo desde el punto de vista de inmunidad celular ${ }^{8}$, lo que aumenta la posibilidad de sufrir DLP. El principal factor de riesgo para el desarrollo de DLP es la primoinfección, lo que explica que la incidencia de DLP sea más alta en niños (4-22\% en varias series) comparado con los adultos que es del 1 al 2\%. Aproximadamente el 50\% de los pacientes menores de 18 años son seronegativos al memento del trasplante, comparado con el $90 \%$ de los adultos 9 ; por lo que se estima que al momento del evento ocurre primoinfección en el $67 \%$ de los pacientes pediátricos ${ }^{10}$. Esto sugiere que el seguimiento a los pacientes trasplantados con respecto a su estado de infección por EBV sería ideal para hacer intervenciones terapéuticas precoces 
encaminadas a evitar las complicaciones propias de la enfermedad.

Una de las formas más útiles para este fin es la cuantificación del genoma viral (carga viral de EBV), aunque se debe tener en cuenta que existen muchas limitaciones con respecto al diagnóstico y seguimiento de estos pacientes con esta técnica tales como escogencia de la muestra adecuada (sangre total, suero, plasma, tejido), los valores de carga viral para definir enfermedad y la falta de estandarización de los procedimientos moleculares para la cuantificación de la carga viral de EBV entre los laboratorios, ya que agrega una incógnita más a la definición ideal del punto de corte a partir del cual el clínico tomará decisiones diagnósticas y terapéuticas ${ }^{6}$.

Teniendo en cuenta la importancia que está adquiriendo el trasplante hepático y la alta seroprevalencia para la infección por EBV, el objetivo de este artículo es describir una serie de casos de pacientes pediátricos con trasplante hepático y diagnóstico de infección por EBV en una institución de Medellín, Colombia, la relación de la carga viral con el uso de inmunosupresores y antivirales y su seguimiento en el tiempo.

\section{Descripción de los casos}

Para la selección de pacientes se hizo una revisión retrospectiva de siete historias clínicas de pacientes pediátricos con trasplante hepático a quienes se les diagnosticó infección por EBV y asistieron al Hospital Pablo Tobón Uribe durante el período comprendido entre junio de 2006 y septiembre de 2013. Los casos se escogieron al azar. Los datos que se tomaron fueron: edad al momento del trasplante, género, diagnóstico que motivó el trasplante, tiempo transcurrido entre el trasplante y la detección de la primera carga viral positiva para EBV, cargas virales subsecuentes, niveles de transaminasas, nivel de bilirrubinas y gammaglutamiltranspeptidasa. Además, se obtuvieron datos acerca del manejo recibido, medicamentos inmunosupresores y niveles plasmáticos de ciclosporina y tacrolimus. El diagnóstico de DLP fue hecho por un patólogo quien estudió una biopsia del sitio afectado.

La forma de seguimiento y decisiones terapéuticas al momento de la detección de carga viral para EBV se hicieron en conjunto entre hepatología y enfermedades infecciosas. Se solicitó la carga viral de forma semanal y se inició manejo con antivirales asociados a disminución de la inmunosupresión al detectar carga viral en sangre total. Para el diagnóstico de rechazo se usaron métodos bioquímicos como la medición de los niveles de transaminasas, gammaglutamiltranspeptidasa, bilirrubinas y se realizó biopsia hepática. El método de purificación y amplificación de ADN se hizo según las recomendaciones del fabricante(QIAGEN, Duesseldorf, Germany) ${ }^{11}$ y para la cuantificación de la carga viral se usó el equipo de reacción en cadena de polimerasa en tiempo real de ROCHE, Lightcycler 2.0.

De los siete pacientes se incluyeron seis hombres. La edad promedio de los pacientes al momento del trasplante fue de 28,4 meses (entre 21 - 36 meses) y el tiempo promedio transcurrido entre el trasplante y la primera cuantificación positiva de carga viral fue de 5,3 meses (0,6 - 19,5 meses). Entre las patologías que motivaron el trasplante esta la colestasis familiar progresiva maligna, atresia de las vías biliares, fibrosis hepática congénita, tumor quístico gigante, entre otras. Uno de los pacientes presentó DLP pero no coincidio con el que presentó la mayor carga viral para EBV. Entre los medicamentos inmunosupresores usados se encuentran ciclosporina, tacrolimus, prednisolona, micofenolatomofetil y azatioprina. Otras características clínicas y epidemiológicas se muestran en la tabla 1. En la tabla 2 se puede observar la relación observada entre el uso de medicamentos antivirales y los cambios en la carga viral.

En el grupo tratado con medicamentos inmunosupresores los hallazgos fueron más uniformes aunque no constantes (Ver Tabla 3). En el paciente 1, la carga viral más alta se correlacionó con los niveles de ciclosporina más altos. En el paciente 2 los bolos de metilprednisolona usados para rescate de rechazo indujeron un aumento en la cantidad de copias de EBV en sangre periférica, además la carga viral más alta fue observada en el momento de mayor concentración plasmática de tacrolimus (Ver Figura 1). En el paciente 3 se observó disminución de la carga viral al disminuir las concentraciones de ciclosporina y tacrolimus, además se notó un aumento de 1700\% (de 37300 a 650000 copias/mL) al iniciar micofenolato mofetil (Ver Figura 2). El paciente 7 tuvo reactivación de la carga viral asociado a fiebre y aparición de megalias generalizadas. Se hizo diagnóstico histológico de DLP y se encuentra carga viral para EBV de 1344000 copias/mL, se inició esquema quimioterapéutico con rituximab, prednisolona, ciclofosfamida, doxorrubicina y vincristina con 
curación del DLP asociado a cargas virales indetectables para EBV. En la tabla 4 se resumen los medicamentos recibidos por los pacientes incluidos en el presente trabajo. Todos recibieron ganciclovir e Inmunoglobina (Ig) e Intravenosa (IV) Citomegalovirus (CMV) como parte de su esquema antiviral.

Tabla 1. Características clínicas y por laboratorio de los pacientes trasplantados hepáticos con infección activa por VEB

\begin{tabular}{|c|c|c|c|c|c|c|c|c|c|}
\hline Paciente & $\begin{array}{l}\text { Patología de } \\
\text { base }\end{array}$ & $\begin{array}{l}\text { Hallazgos al momento } \\
\text { del diagnóstico de } \\
\text { infección por EBV }\end{array}$ & $\begin{array}{c}\text { Rango de } \\
\text { carga viral en } \\
\text { copias/mL } \\
\text { (mediana) }\end{array}$ & $\begin{array}{c}\text { Promedio } \\
\text { de niveles } \\
\text { de } \\
\text { AST/ALT } \\
\text { (UI/L) }\end{array}$ & $\begin{array}{c}\text { Promedio } \\
\text { de } \\
\text { niveles } \\
\text { de GGT } \\
\text { (UI/L) }\end{array}$ & $\begin{array}{c}\text { Promedio } \\
\text { de niveles } \\
\text { de } \\
\text { bilirrubina } \\
\text { total (mg/ } \\
\text { dL) }\end{array}$ & $\begin{array}{l}\text { Promedio } \\
\text { de } \\
\text { niveles de } \\
\text { bilirrbuina } \\
\text { directa } \\
\text { (mg/dL) }\end{array}$ & $\begin{array}{c}\text { Tiempo de } \\
\text { seguimiento } \\
\text { con } \\
\text { cuantificación } \\
\text { de carga viral } \\
\text { (meses) }\end{array}$ & $\begin{array}{c}\text { Causa } \\
\text { de } \\
\text { muerte }\end{array}$ \\
\hline 1 & $\begin{array}{l}\text { Colestasis } \\
\text { familiar } \\
\text { progresiva }\end{array}$ & $\begin{array}{l}\text { Aumento de } \\
\text { transaminasas y fiebre }\end{array}$ & $\begin{array}{c}0-42600000 \\
(322000)\end{array}$ & $660 / 508$ & 177 & 4,2 & 2,8 & 30 & $\begin{array}{c}\text { Falla } \\
\text { hepática }\end{array}$ \\
\hline 2 & $\begin{array}{c}\text { Atresia de vías } \\
\text { biliares }\end{array}$ & Fiebre & $\begin{array}{l}0-2200000 \\
(58200)\end{array}$ & $230 / 247$ & 261 & 3,2 & 2,2 & 34 & $\begin{array}{l}\text { Falla } \\
\text { orgánica } \\
\text { múltiple }\end{array}$ \\
\hline 3 & $\begin{array}{l}\text { Fibrosis } \\
\text { hepática } \\
\text { congénita }\end{array}$ & Rechazo agudo & $\begin{array}{l}0-1270000 \\
(100000)\end{array}$ & $124 / 148$ & 72 & 3,1 & 1,9 & 45 & - \\
\hline 4 & $\begin{array}{l}\text { Tumor quístico } \\
\text { gigante }\end{array}$ & $\begin{array}{c}\text { Mononucleosis } \\
\text { infecciosa }\end{array}$ & $\begin{array}{l}20200-7430 \\
000(470000)\end{array}$ & $254 / 268$ & 1085 & 10,1 & 7,1 & 22 & Sepsis \\
\hline 5 & $\begin{array}{l}\text { Falla hepática } \\
\text { por ácido } \\
\text { valpróico }\end{array}$ & $\begin{array}{l}\text { Fiebre, inapetencia, } \\
\text { síntomas gripales }\end{array}$ & $\begin{array}{l}0-2110000 \\
(110000)\end{array}$ & $53 / 54$ & 25 & 1,07 & 0,4 & 41 & - \\
\hline 6 & $\begin{array}{c}\text { Hepatitis } \\
\text { neonatal por } \\
\text { CMV }\end{array}$ & $\begin{array}{l}\text { Síntomas gripales, } \\
\text { esplenomegalia }\end{array}$ & $\begin{array}{l}0-96700 \\
(33800)\end{array}$ & $130 / 104$ & 96 & 1,2 & 0,8 & 15 & - \\
\hline 7 & $\begin{array}{l}\text { Colestasis } \\
\text { familiar } \\
\text { progresiva }\end{array}$ & $\begin{array}{c}\text { Adenomegalias, } \\
\text { hepatoesplenomegalia }\end{array}$ & $\begin{array}{l}20560-1344 \\
000(31040)\end{array}$ & $184 / 155$ & 466 & 4,5 & 3,4 & 24 & --- \\
\hline
\end{tabular}

Fuente: Autores.

Dentro de los medicamentos antivirales usados el que reportó mayores efectos adversos fue ganciclovir el cual indujo leucopenia en los pacientes 1 y 3 por lo que requirieron aplicación de factor estimulante de colonias de granulocitos con buena respuesta al mejorar su recuento de leucocitos. A pesar de esto, es posible que estos hallazgos hematológicos sean de origen multifactorial teniendo en cuenta que estos pacientes usualmente reciben muchos medicamentos con efectos adversos similares a los causados por ganciclovir y valganciclovir.

\section{Discusión}

Los pacientes trasplantados son un reto desde el punto de vista de las enfermedades infecciosas. Para los hospederos seronegativos para EBV existe un gran riesgo cuando el donante es seropositivo para este virus y sus células $B$ infectadas ingresan al organismo del receptor ${ }^{12}$. Los órganos con mayor carga viral son intestino y pulmón pues tienen mayor cantidad de tejido linfoide potencialmente infectado con EBV y dependerá de la capacidad inmune del hospedero el poder controlar la infección ${ }^{6}$. El espectro de la enfermedad en pacientes trasplantados con infección por EBV va desde una infección viral inespecífica hasta mononucleosis infecciosa y DLP ${ }^{6}$, siendo este último muy importante por su alta tasa de morbimortalidad"1". La aparición de nuevos agentes inmunosupresores y la posibilidad del uso de injertos parciales (de pacientes mayores o donantes adultos vivos) aumenta la posibilidad de primoinfección en 
pacientes pediátricos (seronegativos) receptores de órganos de pacientes mayores (seropositivos) $)^{12}$. Por esto la disponibilidad de los métodos moleculares para seguimiento de estos pacientes es ideal para poder hacer modificaciones en la inmunosupresión y justificar el uso de medicamentos antivirales que deberían disminuir, en teoría, la aparición de estas complicaciones ${ }^{13}$.

Tabla 2. Respuesta de la carga viral para EBV a medicamentos contra citomegalovirus como ganciclovir, valganciclovir, inmunoglobulina contra citomegalovirus

\begin{tabular}{|c|c|c|c|}
\hline Paciente & Medicamento antiviral & Uso & Efecto sobre carga viral \\
\hline 1 & $\begin{array}{l}\text { ganciclovir } \\
\text { Ig IV CMV }{ }^{1} \\
\text { rituximab } \\
\text { valganciclovir }\end{array}$ & $\begin{array}{l}3 \text { meses } \\
\text { Semanal por } 3 \text { dosis } \\
\text { Semanal por } 3 \text { dosis } \\
\text { Permanente }\end{array}$ & $\begin{array}{l}\text { No disminuye } \\
\text { Disminuye pero aumenta al suspender } \\
\text { Indetectable pero reaparece al suspender } \\
\text { Indetectable }\end{array}$ \\
\hline 2 & $\begin{array}{l}\text { Ciclo número } 1 \\
\text { ganciclovir } \\
\text { Ciclo número } 2 \\
\text { ganciclovir } \\
\text { Ig IV CMV }\end{array}$ & $\begin{array}{l}3 \text { semanas } \\
\text { Cada semanas } \\
\text { dosis }\end{array}$ & $\begin{array}{l}\text { Disminuye de } 2200000 \text { copias } / \mathrm{mL} \text { a } 363000 \text { copias/ } \\
\mathrm{mL}^{3} \\
\text { Indetectable } \\
\text { Aumenta de } 149000 \text { copias } / \mathrm{mL} \text { a } 248000 \text { copias } / \mathrm{mL}^{4}\end{array}$ \\
\hline 3 & $\begin{array}{l}\text { ganciclovir } \\
\lg \text { IV CMV/valganciclovir } \\
\text { ganciclovir }\end{array}$ & $\begin{array}{l}3 \text { semanas } \\
\text { Semanal por } 3 \\
\text { dosis/permanente } \\
\text { Permanente }\end{array}$ & $\begin{array}{l}\text { Disminuye de } 149000 \text { copias } / \mathrm{mL} \text { a } 116000 \text { copias/Ml } \\
\text { Cargas virales varían entre } 78000 \text { copias } / \mathrm{mL} \text { y } 510000 \\
\text { copias } / \mathrm{mL} \\
\text { Cargas virales indetectables por } 3 \text { meses }^{5}\end{array}$ \\
\hline 4 & $\begin{array}{l}\text { ganciclovir } \\
\text { Ig IV CMV }\end{array}$ & $\begin{array}{c}\text { Permanente } \\
\text { Cada semana por } 5 \\
\text { dosis }\end{array}$ & $\begin{array}{l}\text { No disminuye } \\
\text { No disminuye }\end{array}$ \\
\hline 5 & $\begin{array}{l}\text { ganciclovir } \\
\text { valganciclovir } \\
\text { Ig IV CMV }\end{array}$ & $\begin{array}{c}2 \text { semanas } \\
\text { Permanente } \\
\text { Semanal por } 4 \\
\text { semanas }\end{array}$ & $\begin{array}{l}\text { Indetectable } \\
\text { Aumenta de } 111000 \text { copias } / \mathrm{mL} \text { a } 2110000 \text { copias } / \mathrm{mL} \\
\text { Indetectable }\end{array}$ \\
\hline 6 & Ig IV CMV/valganciclovir & $\begin{array}{c}\text { Semanal por } 3 \\
\text { dosis/permanente }\end{array}$ & Indetectable después de 2 meses \\
\hline 7 & ganciclovir/lg IV & $\begin{array}{c}\text { Permanente/ } \\
\text { semanal }\end{array}$ & Indetectable de forma temporal \\
\hline
\end{tabular}

'Inmunoglobulina contra citomegalovirus

${ }^{2}$ Recibe 3 dosis de rituximab de forma concomitante

${ }^{3}$ Se disminuyen dosis de tacrolimus y prednisolona

${ }^{4} \mathrm{Se}$ aumenta dosis de tacrolimus y recibe bolos de metilprednisolona

${ }^{5}$ Recibió rituximab semanal por 4 dosis

${ }^{6}$ Se suspende concomitantemente inmunosupresión

Fuente: Autores.

La medición de la carga viral es cada vez más usada como método de seguimiento en los pacientes con infección por EBV, pues permite hacer modificaciones en el tratamiento inmunosupresor y evalúa los cambios vistos con dicha intervención ${ }^{14}$. Uno de los protocolos disponibles para seguimiento y manejo de los pacientes con trasplante de órgano sólido es el utilizado en el hospital de niños de Pittsburgh, Estados Unidos, en donde definen enfermedad por EBV como aparición de signos y síntomas sugestivos como fiebre, faringitis, hepatoesplenomegalia, diarrea, ascitis, hepatitis, neumonitis, hipertrofia amigdalina, linfadenopatías periféricas, aumento de enzimas hepáticas, fatiga, malestar, hiporexia,

pérdida de peso y dolor abdominal en presencia de una carga viral positiva que es usualmente mayor de 16000 copias $/ \mathrm{mL}$ de sangre total. Lo anterior con el propósito de iniciar terapia preventiva (disminución de la inmunosupresión) o dirigida (disminución de la inmunosupresión asociado al uso de ganciclovir). Con respecto al DLP, Lee y colaboradores, demostraron que el seguimiento con carga viral a los pacientes trasplantados cada dos semanas en los primeros tres meses y cada uno a tres meses luego de tres meses de trasplante, se asoció a una disminución del $16 \%$ al $2 \%$ en DLP gracias a los datos obtenidos y basándose en estos para modificar el nivel de inmunosupresión ${ }^{15}$. 
Tabla 3. Efecto de los medicamentos inmunosupresores en relación a la carga viral por EBV

\begin{tabular}{|c|c|c|c|}
\hline Paciente & $\begin{array}{l}\text { Cambios en } \\
\text { la dosis del } \\
\text { medicamento }\end{array}$ & Medicamento & $\begin{array}{c}\text { Carga } \\
\text { viral EBV }\end{array}$ \\
\hline 1 & $\uparrow$ & Ciclosporina & $\uparrow$ \\
\hline 2 & $\begin{array}{l}\uparrow \\
\uparrow\end{array}$ & $\begin{array}{c}\text { Metilprednisolona } \\
\text { Tacrolimus }\end{array}$ & $\uparrow$ \\
\hline 3 & $\begin{array}{l}\downarrow \\
\downarrow\end{array}$ & $\begin{array}{l}\text { Ciclosporina } \\
\text { Tacrolimus }\end{array}$ & $\downarrow$ \\
\hline 4 & $\begin{array}{l}\downarrow \\
\uparrow\end{array}$ & $\begin{array}{c}\text { Tacrolimus } \\
\text { Metilprednisolona }\end{array}$ & $\begin{array}{l}\downarrow \\
\uparrow\end{array}$ \\
\hline 5 & $\begin{array}{l}\downarrow \\
\downarrow\end{array}$ & $\begin{array}{l}\text { Azatropina } \\
\text { suspendida } \\
\text { ciclosporina }\end{array}$ & $\begin{array}{l}\downarrow \\
\downarrow\end{array}$ \\
\hline 6 & Sin cambios & $\begin{array}{l}\text { Azatioprina } \\
\text { Tacrolimus }\end{array}$ & $\begin{array}{c}\text { Sin } \\
\text { cambios }\end{array}$ \\
\hline 7 & $\uparrow$ & Metilprednisolona & $\uparrow$ \\
\hline
\end{tabular}

Fuente: Autores.

Tabla 4. Resumen de intervenciones terapéuticas en los pacientes trasplantado con infección activa por EBV

\begin{tabular}{|c|c|c|c|c|c|}
\hline Paciente & Ganciclovir & Valganciclovir & $\lg$ IV & $\begin{array}{l}\text { Ig IV } \\
\text { CMV }\end{array}$ & Rituximab \\
\hline 1 & $x$ & $x$ & & $x$ & $x$ \\
\hline 2 & $x$ & $x$ & & $x$ & \\
\hline 3 & $x$ & $x$ & $x$ & $x$ & $x$ \\
\hline 4 & $x$ & $x$ & & $x$ & $x$ \\
\hline 5 & $x$ & $x$ & & $x$ & \\
\hline 6 & $x$ & & $x$ & $x$ & \\
\hline 7 & $x$ & $x$ & $x$ & $x$ & $x$ \\
\hline
\end{tabular}

Fuente: Autores.

Con respecto al tipo de muestra, se recomienda que la sangre total sea usada para medir la carga viral pues permite evaluar todos los componentes sanguíneos que pueden albergar ADN viral ${ }^{16}$. Esta recomendación no es aplicable para todas las enfermedades asociadas a la infección por EBV por lo que debe individualizarse cada caso. Por ejemplo, cuando la enfermedad desarrollada es carcinoma nasofaríngeo, la mayoría del genoma de EBV está en los tejidos, motivo por el cual las muestras de sangre total no son adecuadas ${ }^{17}$.
La medición de la carga viral para EBV por medio de técnicas moleculares es un procedimiento recomendable en los pacientes con trasplante de órgano sólido, pues además de permitir el seguimiento de los niveles de carga viral, también se comporta como un indicador del grado de inmunosupresión al que está expuesto el paciente debido a que para poder controlar la viremia se requiere un sistema inmune competente, sobre todo desde el punto de vista de la inmunidad celular mediada por linfocitos $\mathrm{T}^{18}$. El punto de corte para hablar de carga viral alta no ha sido establecido y varía entre estudios. Algunos autores sugieren 1500 copias $/ \mathrm{mL}^{18}$, otros permiten hasta 10000 copias $/ \mathrm{mL}^{19}$ y 16000 copias/ $\mathrm{mL}^{19}$, de todos modos, los autores sugieren realizar estudios prospectivos más completos para aclarar mejor estos valores. En la institución del presente estudio el seguimiento hecho a los pacientes con infección por EBV no se hace con un protocolo definido. El protocolo usado en el hospital de niños de Pittsburgh sugiere seguimiento de la carga viral en intervalos definidos y se presenta en la Tabla 5.

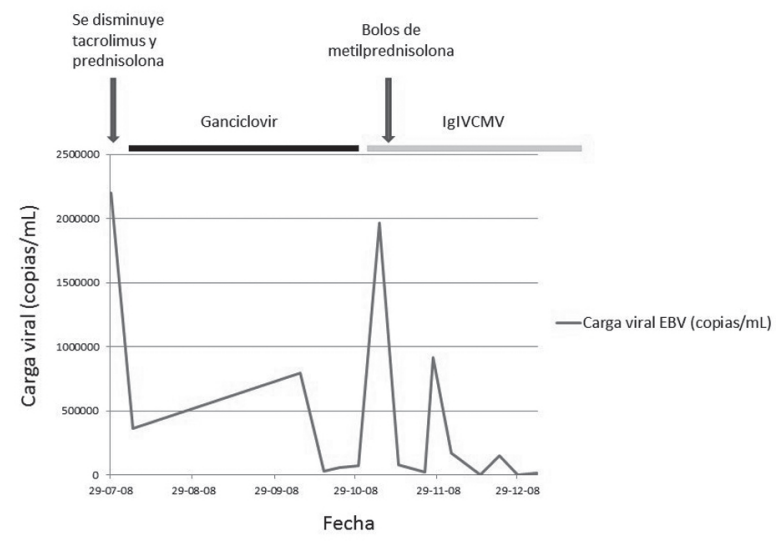

Figura 1. Paciente 2 - Segmento de cinco meses de seguimiento. Se observa una disminución de la carga viral al disminuir tacrolimus y prednisolona, además ocurrió un aumento en la carga viral con los bolos de metilprednisolona

Fuente: Autores.

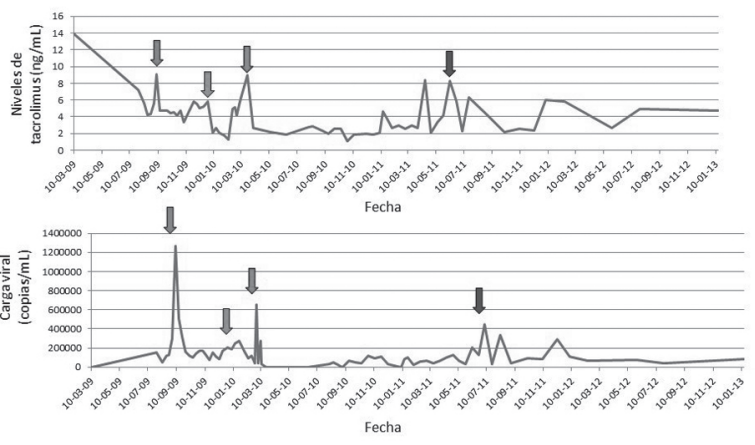

Figura 2. Paciente 3. Se observan aumentos en la carga viral que coinciden con algunas de las concentraciones mas altas de tacrolimus

Fuente: Autores. 
El nivel de carga viral para EBV y el tiempo que esta última permanece alto también han sido materia de debate de diferentes estudios; algunos autores sugieren que las cargas virales altas y sostenidas, definida como niveles superiores a 16000 copias/ $\mathrm{mL}$, por lo menos en el $50 \%$ de las ocasiones en que fuera medida, dentro de un periodo de seis meses se asocian con la aparición de complicaciones linfoproliferativas del EBV ${ }^{13,21}$. Otros han reportado que ser receptor seronegativo para EBV y donante seropositivo, tener el alelo HLA-DR7 y el uso de terapia inmunosupresora intensa son los factores más frecuentemente asociados a enfermedad por EBV en trasplantados ${ }^{19}$.

Tabla 5. Protocolo de seguimiento de la carga viral para EBV en el hospital de niños de Pittsburgh

\begin{tabular}{|c|c|}
\hline $\begin{array}{c}\text { Tiempo postrasplante } \\
\text { (meses) }\end{array}$ & $\begin{array}{c}\text { Intervalo de seguimiento } \\
\text { con carga viral }\end{array}$ \\
\hline $0-3$ & Cada 2 semanas \\
\hline $3-6$ & Cada mes \\
\hline $6-12$ & Cada 2 meses \\
\hline $12-24$ & Cada 3 meses \\
\hline Mas de 24 & Cada 6 meses \\
\hline
\end{tabular}

Fuente: Catalán P, Alba A. Prophylaxis against Epstein Barr disease in pediatric and adult patients undergoing solid organ and hematopoietic stem cells transplantation. Rev Chilena Infectol. 2012;29 Suppl 1:S29-31.

Scheenstra y colaboradores, reportan que los pacientes seronegativos para EBV previos al trasplante suelen tener cargas virales más altas al infectarse. Además, el hecho de tener cargas virales altas no es útil para diagnosticar DLP, pero si para identificar los pacientes que se encuentran en riesgo para desarrollarla ${ }^{13}$. Green y colaboradores encontraron que tener cargas virales altas de forma persistente no se comportó como un factor de riesgo importante para complicaciones linfoproliferativas en pacientes con trasplante hepático, lo cual difiere a lo visto en trasplante cardiaco en el mismo centro hospitalario ${ }^{20}$.

Desde el punto de vista del tratamiento, no existe mucha claridad con la utilidad de intervenciones medicamentosas, principalmente con antivirales ${ }^{22}$. La terapia anticipada con miras a disminuir la carga viral de EBV se basa principalmente en la modulación de la inmunosupresión. Catalán y colaboradores sugieren hacer seguimiento de carga viral cada dos a cuatro semanas los primeros seis meses, luego cada dos a tres meses hasta el año y cada cuatro a seis meses hasta los dos años. Ante la aparición de carga viral sobre el punto de corte establecido de 1000 copias $/ \mathrm{mL}$ en sangre total en pacientes seronegativos, o más de 10000 copias/mL en pacientes seropositivos, se debe repetir en tres a siete días; si la carga viral aumenta de forma logarítmica recomiendan disminuir al máximo la inmunosupresión suspendiendo anti-proliferativos y bajando niveles de calcineurínicos a la mitad y además hacer evaluación clínica e imageneológica en busca de DLP. En caso de no encontrarse evidencia de la enfermedad se recomienda seguimiento seriado de la carga viral'22. En los pacientes estudiados se observó de forma individual una respuesta más predecible en la carga viral a las modificaciones en la inmunosupresión.

La utilidad de los medicamentos antivirales como ganciclovir y su prodroga oral valganciclovir, no está muy clara debido al estado de latencia en el que usualmente se encuentra EBV en los pacientes trasplantados. A pesar de esto, Venturi y colaboradores evaluaron la respuesta al ganciclovir y valganciclovir en pacientes pediátricos con trasplante hepático. A los 30 días de tratamiento encontraron respuesta completa (carga viral indetectable) en el 34\% de los pacientes tratados comparado con el $6 \%$ en pacientes no tratados; estos resultados mostraron ser estadísticamente significativos, pero a pesar de lo anterior, luego de 60 días de seguimiento posterapia no se encontraron diferencias significativas ${ }^{23}$. Hierro y colaboradores, evaluaron la eficacia y seguridad del valganciclovir en pacientes con trasplante hepático infectados con EBV y sugieren que el tratamiento prolongado con el medicamento ( 8 meses en promedio) logró tornar indetectable la carga viral en el $47 \%$ de los pacientes aun sin modificar el nivel de inmunosupresión, permaneciendo negativa durante el seguimiento (5 meses en promedio) ${ }^{24}$. En los pacientes del presente estudio se observó una respuesta irregular asociada al uso de los medicamentos antivirales aunque sigue siendo una opción de manejo en estos pacientes.

El uso de rituximab en trasplante hepático se recomienda en el contexto de un DLP establecido y puede ser usado como monoterapia ${ }^{25}$ o como parte de un manejo integral constituido por disminución en la inmunosupresión, quimioterapia (esquema CHOP - ciclofosfamida, doxorubicina, vincristina y prednisolona), control local (cirugía, radioterapia) e inmunoterapia adoptiva (infusión de linfocitos $\mathrm{T}$ citotóxicos autólogos) ${ }^{26}$. Orentas y colaboradores reportaron que el rituximab puede tornar indetectable la carga viral de EBV o disminuirla de forma marcada, 
seguida de un rebote en la carga viral lo cual sería explicado por la compleja relación que existe entre el efecto del rituximab y la capacidad de aclaramiento de las células infectadas ${ }^{21}$.

Con la evidencia médica actual, la estrategia más útil para el control de la infección por EBV en el paciente trasplantado es la modulación de la inmunosupresión lo cual permitiría al hospedero tener una respuesta inmune más efectiva y así disminuir o hacer indetectable la viremia. Esto último es importante no solo desde el punto de vista de la infección por EBV y sus consecuencias (hepatitis, rechazo, síndrome mononucleósico) sino también para disminuir la posibilidad que se presente un DLP.

El uso de microarrays es uno de los campos más promisorios para evaluar de forma objetiva la relación entre EBV y el hospedero. Allen y colaboradores, presentaron un trabajo en el cual evaluaron, por medio de esta técnica, la expresión génica del hospedero en respuesta a la infección por EBV teniendo en cuenta el nivel de carga viral y su relación con la aparición de DLP encontrando diferencias en los grupos de pacientes estadificados según carga viral y la expresión de algunos genes diferenciales. Aunque la relación de esta expresión génica con la enfermedad es desconocida, es un punto de partida para investigaciones futuras ${ }^{27}$.

\section{CONClusiones}

A pesar de las muchas opciones terapéuticas disponibles para los virus de la familia Herpesviridae, según lo encontrado en la literatura actual y lo visto en este grupo de pacientes, el grado de inmunosupresión parece ser el principal factor implicado en el control de la replicación del EBV teniendo en cuenta la limitada respuesta observada en los niveles de carga viral al momento de usar los diferentes medicamentos antivirales disponibles. Se observó una respuesta más predecible con la modificación de la inmunosupresión, mostrando incremento en la carga viral para EBV al momento de usar dosis altas de esteroides y al aumentar las concentraciones de ciclosporina y tacrolimus.

\section{Referencias Bibliográficas}

1. Jenson HB. Epstein-Barr Virus. Pediatrics in Review. 2011;32(9):375-83;375-84.

2. Pordeus V, Barzilai O, Sherer Y, Luiz RR, Blank M, Bizarro N, et al. A latitudinal gradient study of common anti-infectious agent antibody prevalence in Italy and Colombia. Isr Med Assoc
J. 2008;10(1):65-8.

3. De Roos AJ, Martinez-Maza O, Jerome KR, Mirick DK, Kopecky $\mathrm{KJ}$, Madeleine MM, et al. Investigation of epstein-barr virus as a potential cause of B-cell non-Hodgkin lymphoma in a prospective cohort. Cancer Epidemiol Biomarkers Prev. 2013;22(10):1747-55. Epub 2013 Jul 24.

4. Slyker JA, Casper C, Tapia K, Richardson B, Bunts L, Huang ML, et al. Clinical and virologic manifestations of primary EpsteinBarr virus (EBV) infection in Kenyan infants born to HIV-infected women. J Infect Dis. 2013;207(12):1798-806. Epub 2013 Mar 14.

5. Tiao G, Alonso MH, Ryckman FC. Liver transplantation in children. In: Suchy FJ, Sokol RJ, Balistreri WF, editors. Liver disease in children. 18a Ed. UK: Cambridge University Press; 2007. p. 975-93

6. Green M, Michaels MG. Epstein-Barr virus infection and posttransplant lymphoproliferative disorder. Am J Transplant. 2013;13 Suppl 3:41-54; quiz 54.

7. Wiederkehr JC, Coelho IM, Avilla SG, e Silva EM, Schuller S, Ouno $\mathrm{DD}$, et al. Prevalence of posttransplantation lymphoproliferative disease in pediatric liver transplant recipients. Transplant Proc. 2010;42(2):521-2.

8. Martelius T, Lappalainen M, Aalto SM, Nihtinen A, Hedman K, Anttila VJ. Clinical characteristics, outcome and the role of viral load in nontransplant patients with Epstein-Barr viraemia. Clin Microbiol Infect. 2010;16(6):657-62.

9. Allen U, Alfieri C, Preiksaitis J, Humar A, Moore D, Tapiero B, et al. Epstein-Barr virus infection in transplant recipients: Summary of a workshop on surveillance, prevention and treatment. Can J Infect Dis. 2002;13(2):89-99.

10. Ozçay F, Arslan H, Bilezikçi B, Sevmiş S, Moray G, Haberal M. The role of valacyclovir on Epstein-Barr virus viral loads in pediatric liver transplantation patients. Transplant Proc. 2009;41(7):2878-80.

11. Qiagen (2012). QIAamp® DNA Mini and Blood Mini Handbook. 3th Ed.

12. Narkewicz MR, Green M, Dunn S, Millis M, McDiarmid S, Mazariegos G, et al. Decreasing incidence of symptomatic EpsteinBarr virus disease and posttransplant lymphoproliferative disorder in pediatric liver transplant recipients: report of the studies of pediatric liver transplantation experience. Liver Transpl. 2013;19(7):730-40.

13. Scheenstra R, Verschuuren EA, de Haan A, Slooff MJ, The TH, Bijleveld CM, et al. The value of prospective monitoring of Epstein-Barr virus DNA in blood samples of pediatric liver transplant recipients. Transpl Infect Dis. 2004;6(1):15-22.

14. Jang JY, Kim KM, Lee YJ, Lee SG, Chi HS. Quantitative EpsteinBarr virus viral load monitoring in pediatric liver transplantation. Transplant Proc. 2008;40(8):2546-8.

15. Lee TC, Savoldo B, Rooney CM, Heslop HE, Gee AP, Caldwell $\mathrm{Y}$, et al. Quantitative EBV viral loads and immunosuppression alterations can decrease PTLD incidence in pediatric liver transplant recipients. Am J Transplant. 2005;5(9):2222-8.

16. Kasztelewicz B, Jankowska I, Pawlowska J, Teisseyre J, Grenda R, Pronicki M, et al. Epstein-Barr virus DNA load in peripheral blood mononuclear cells and whole blood from pediatric transplant recipients. Transpl Infect Dis. 2011;13(5):471-9.

17. Kimura H, Ito Y, Suzuki R, Nishiyama Y. Measuring Epstein-Barr virus (EBV) load: the significance and application for each EBVassociated disease. Rev Med Virol. 2008 ;18(5):305-19.

18. San-Juan R, De Dios B, Navarro D, García-Reyne A, Lumbreras C, Bravo D, et al. Epstein-Barr virus DNAemia is an early surrogate marker of the net state of immunosuppresion in solid organ transplant recipients. Transplantation. 2013;95(5):688-93.

19. Höcker B, Fickenscher H, Delecluse HJ, Böhm S, Küsters U, Schnitzler P, et al. Epidemiology and morbidity of EpsteinBarr virus infection in pediatric renal transplant recipients: a multicenter, prospective study. Clin Infect Dis. 2013;56(1):84-92.

20. Green M, Soltys K, Rowe DT, Webber SA, Mazareigos G. Chronic high Epstein-Barr viral load carriage in pediatric liver transplant recipients. Pediatr Transplant. 2009;13(3):319-23.

21. Orentas RJ, Schauer DW, Ellis FW, Walczak J, Casper JT, Margolis DA. Monitoring and modulation of Epstein-Barr virus loads in pediatric transplant patients. Pediatr Transplant. 2003;7(4):305-14.

22. Catalán P, Alba A. Prophylaxis against Epstein Barr disease in pediatric and adult patients undergoing solid organ and hematopoietic stem cells transplantation. Rev Chilena Infectol. 2012;29Suppl 1:S29-31. 
23. Venturi C, Bueno J, Gavalda J, Tórtola T, Pou L, Medina A, et al. Impact of valganciclovir on Epstein-Barr Virus polymerase chain reaction in pediatric liver transplantation: preliminary report. Transplant Proc. 2009;41(3):1038-40.

24. Hierro L, Díez-Dorado R, Díaz C, De la Vega A, Frauca E, Camarena C, et al. Efficacy and safety of valganciclovir in livertransplanted children infected with Epstein-Barr virus. Liver Transpl. 2008;14(8):1185-93.

25. Hayashida M, Ogita K, Matsuura T, Takahashi Y, Nishimoto Y, Ohga S, et al. Successful prolonged rituximab treatment for post-transplant lymphoproliferative disorder following living donor liver transplantation in a child. Pediatr Transplant. 2007;11(6):671-5

26. Kamdar KY, Rooney CM, Heslop HE. Posttransplant lymphoproliferative disease following liver transplantation. Curr Opin Organ Transplant. 2011;16(3):274-80.

27. Allen U, Barton M, Beyene J, Hu P, Khodai-Booran N, Hébert D, et al. Gene expression using microarrays in transplant recipients at risk of EBV lymphoproliferation after organ transplantation: preliminary proof-of-concept. Pediatr Transplant. 2009;13(8):990-8. 